\title{
Effect of Social Correlates on Employee Performance in Public Health Facilities, Turbo Sub County, Kenya
}

\author{
Mercy Adoyo K'osuri", Ann Kalei" and Robert Onyango^ \\ \#omo Kenyatta University of Agriculture and Technology, Kenya \\ ^Masinde Muliro University of Science and Technology, Kenya \\ Received 16 Aug 2018, Accepted 19 Oct 2018, Available online 21 Oct 2018, Vol.6 (Sept/Oct 2018 issue)
}

\begin{abstract}
In this globalized era, organizations certainly require employees who are high achievers. This calls for a high demand for professionals with skills, hence organizations are virtually required to embrace their preferences through socially innovative practices. Civil service employees in Kenya, who include the Ministry of Health staff performance is below expectations thus service delivery is compromised. In this regard the current study was designed to assess the effect of social correlates on employees' performance in the public health sector in Turbo Sub-County. The study was guided by the following specific objectives: To examine the effect of supervisors support on employee performance and to analyze the effect of employee participation on employee performance. Conservation of Resources Theory and Social Exchange Theory had the potential to provide a conceptual guide in maximizing employee performance. The study adopted a descriptive survey design based on samples drawn from across the public health facilities in Turbo Sub-County. The target population was 332. A two-stage sampling technique was adopted where cluster random sampling was used to select the Public health facilities after which simple random sampling were used to select respondents within the facilities. The study used Krejcie\& Morgan table,(1970) to calculate the sample size which was 181 respondents. Data was collected by use of self-administered questionnaires. Data analysis was done by use of both inferential and descriptive statistics using SPSS version 20. Results of multiple regressions revealed that social correlates jointly and independently influenced employee performance in public health facilities in Turbo Sub-County, Kenya. Jointly the two constructs namely supervisors support and employee participation contributed $51.4 \%$ of the variation in employee performance (Adjusted $R$ Square $=0.514$ ). There was a positive and significant correlation between supervisors support and employee participation was: $r=.660^{*}, r=.450^{*}$ to employee performance. All these together led to the rejection of the null hypothesis. This implies that the management of public health facilities should pay high premiums in strategically formulating and implementing social correlates which can effectively galvanize employee motivation and performance. Social correlates should be bundled through mutually consistent policies to enhance their synergy in achieving high employee performance.
\end{abstract}

Keywords: Social correlates and Employee performance

\section{Background}

In the advent of a competitive and globalized era, organizations certainly require employees who are high achievers. This calls for a high demand for professionals, hence organizations are virtually required to embrace their preferences through socially innovative practices (Gerald \& White, 2015). Social set of connections can be affected by both the occurrence and assessment of stressful life occasion, social norms in the workplace which affect performance directly (Benish \& Raza, 2017). Therefore the most vital issue that deserves attention is

*Corresponding author's ORCID ID: 0000-0003-3323-3313 DOI: https://doi.org/10.14741/ijmcr/v.6.5.20 to deal with stressful facet by social support which would warrant an increase in employee performance. This is underscored by the fact that organizations need highly performing individuals in order to accomplish their goals and finally achieve a competitive edge (Devender, 2014).

Most employees spend more than $50 \%$ of their working hours at the workplace and its environment greatly influences their performance and mental framework (Arindam, 2016). Therefore Supportive workplace environment remains extremely important in preventing chances of burnout and engendering high employee performance. Conversely, when social work environment is not conducive, the mental frame work is upset and poor performance ensues. Employee performance is operationally defined as the extent to 
which an individual completes the duties that are required in order to occupy a given position, which they assume within an organization (Conway, 2017). Employee performance would increase by means of the expectation that high effort will go ahead to desired performance levels and employees would be rewarded in return. Rewards for service to the organization invokes a sense of appreciation amongst employees, thus motivates them to increases their performance. Employees consider their valuation by their organization, they have their particular views regarding the extent to which boss or supervisors give value and appreciation for their contribution and good care of their wellbeing (Benish \& Raza, 2017).

In this regard, Conservation of Resources Theory (COR) and Social Exchange Theory (SET) have the potential to provide a conceptual guide in maximizing employee performance by considering employees' actual and perceived resources when developing and assigning job roles and tasks (Vinokur-Kaplan, 2009). Resources are conceptualized as anything that individuals personally value and therefore, one may possess personal, social, material, and energy resources (Hobfoll, Vinokur, Pierce \& Lewandowski -Romps, 2012). The things valued by employees appear to be universal, organizations might have no choice but to operate in accordance with people's values and motives for better organizational outcomes (Pheko, 2013). Individual employees who lose social support experience more negative emotional outcomes suggesting that resource mobilization may offset the negative impact of stressful life circumstances which would hinder employee performance (Hobfoll et al., 2012).

Social correlates are psychosocial aspects of work environment which include psychological and social characteristics of work tasks and more general, the organizational environment where work is carried out (Gupta, 2010; Rugulies, 2014). According to Gupta (2010) the increasingly large spans of control and reduced contact between employees and managers in work situations, an over-reliance on employee selection processes as a means of improving performance and commitment may be a less effective approach than effectively managing work environments. According to Abe and Mason (2016) the relationship dimension of social work environment measures the degree of interpersonal interaction in a work environment, such as the social communication exchanges and cohesion among workers, and the friendship and support provided by coworkers and management. It can therefore be inferred that the balance between human factors and occupational factors by use of salient management practices and coworker relations have the capacity to affect an employee's wellbeing and personal functioning at work.

Globally, employee performance is one of the most important dependent variables which has been studied for over a decade (Korkaew \& Suthinee, 2012). Research evidence suggests that globally, health care personnel in public health facilities work under unfavorable conditions hence poor performance (Manyisa \& Elsie, 2017). However United States of America has made steps in solving the problem of performance by initiating pay for performance model so as to improve measures of quality, efficiency and eliminate excessive costs (Asaad \& Assaf, 2011). This system has made the employees in the healthcare to strive for better performance hence solving the problem of poor employee performance. In Denmark and France good perception of work environment was found to be a highly significant determinant of workers wellbeing and employee performance in the health sector (Gupta \& Kristensen, 2008). Majority of studies on employee performance have been conducted in the western nations Nelson (2005); Beith, Eicher and Weil (2007); Adrian, Baconand Redman (2009); Asaad and Assaf (2011); Xu and Bond (2012) but the prevailing view is that the developing countries' cultural context is different from developed countries with the western culture such that western-derived and tested arguments cannot be used to explain and understand organizationa problems in developing African countries (Onyango, Otieno, Bii \& Otieno, 2016). Besides, employee performance management policies are clear and concise in outlining its principles, processes and objectives, however, the extent to which these are followed differ between countries, managers and employees respectively (Saajida \& Ukpere, 2014).

Regionally, insufficient health personnel, in terms of numbers and performance level, are regarded as a major constraint in achieving the Millennium Development Goals (MDGs) for reducing poverty, combating diseases and improving on maternal health in many African countries. According to Carrim (2009); Nilsson (2010) Public sector organizations in South Africa which includes public health facilities find it difficult to overcome the challenge of under performance in most disciplines of their operations. This underperformance impacts negatively on the South African economy and the societies served by public sector organizations, as well as other stakeholders and international relations (Local Government Research Centre, 2009). As a result they receive constant criticism for poor service delivery. In light of aforementioned studies; Chengedzai and Pooe (2013) notes that previous studies focused on socioeconomic perspectives rather than specific dimensional aspects of human behavior that affects employee performance and organizational performance in the public sector in South Africa. Interviews with nurses in Namibia indicated that nurses who comprises the backbone of health services, are overworked and demoralized showing signs of burnout and complained about none recognition for their contributions (Awases, Gbary, Nyoni \& Chatora, 2004). This suggests that issues of performance and factors affecting performance are not adequately addressed in Namibia.

However nurses have a major role to play in providing timely, quality health services as they comprise $80 \%$ of Namibia's health workforce (WHO, 2011). In Uganda's 
case, performance of Ministry of Health staff has been reported to be performing below expectation. This is evidenced by the fact that the utilization rate for outpatient services in government and PNFP units was as low as 0.42 visits per person (Basaza, 2016). This indicates that the Ugandan health employees were not meeting the needs of the population (MoH, 2015). Kinyili (2011) laments that the civil service employees in Kenya, who include the Ministry of Health staffs' performance is below expectations thus service delivery is compromised. Turbo Sub County in Uasin Gishu County remains an invariable victim of, shortage of human resources for health in terms of numbers and skill mix, poor working environment precipitating low staff morale thus poor employee performance (Uasin Gishu Strategic Plan, 2013). All these explain the intermittent closure of health facilities in Uasin Gishu County.

The large number of articles published on the state of working conditions in public health facilities identified and reviewed gives testimony to the fact that the topic is of high priority to health care personnel, policy makers and researchers (Manyisa \& Elsie, 2017). In spite of this, improving the productivity and performance of health care workers in order to enhance efficiency in health interventions still remains a major challenge for African countries (Awases, Bezuidenhout \& Roos, 2013). In Kenya the trend has continued hence calling to question the effect of social factors such as supervisors support, employee participation, knowledge sharing and procedural justice on employee performance. These social factors were adopted from Scheper sand Van Den Berg (2007); Sayyed and Ebrahimian (2012);Min, Tumurpureu and Jae (2013) who only looked at how these factors affects employee satisfaction although these social factors affecting employee performance differ in priority depending on the context. The current study was a dispatch from Schepers and Van Den Berg (2007), Sayyed and Ebrahimian (2012); Min, Tumurpureu and Jae (2013) study by looking at how social correlates affects employee performance in the public sector in the Kenyan context in order to fill in the existing gap in literature.

\subsection{Statement of the Problem}

The County Human Resource for Health Strategic Plan is the hallmark for addressing health workers' performance, appraisal, reward, motivation, capacity building and employee' welfare amongst other issues. Ideally, these were brought into place to help galvanize maximal employee performance in order to help achieve public service reforms, Millennium Development Goals (MDGs) and realization of Vision 2030 through the health workforce (Kassachoon \& Siminyu, 2014). Despite such elaborate and sound policies, achieving the ambitious health milestone remains a mirage. The ministry still faces overwhelming challenges due to the inability to attract and retain competent, satisfied and motivated health workers in the public health facilities which has compromised their performance $(\mathrm{MOH}, 2015$; Githinji, 2017; Njiru, 2008). Turbo Sub- County remains an invariable victim of poor working environment precipitating low staff morale thus poor employee performance (Uasin Gishu Strategic Plan, 2013). In consequence, there has been reduced contribution of the health sectors' GDP by 0.5 percent by the end of the year 2013 (Muchomba \& Karanja, 2015).

This situation has been further compounded by constant health staff unrest which has been witnessed since the advent of county governance thus affecting service delivery and overall performance. These unrests have occasioned poor performance of employee's thus inviting policy-makers and planners to realize that attaining the MDGs is simply not possible if the HR crisis in the health sector is not effectively addressed, despite the increase in financing for health care (Marta, Bettina \& Ulrich, 2014). In this regard, the management of the public health sector should perhaps pay high premiums in improving the social and physical factors of work environment owing to their influence on employee performance. However, majority of studies on employee performance have been conducted in the western nations which includes Asaad and Assaf., 2011; Crabtree, 2013; Hagel et al., 2014; but the prevailing view is that the developing countries' cultural context is different from developed countries with the western culture such that western-derived and tested arguments cannot be used to explain and understand organizational problems in developing African countries (Onyango et al., 2016). In addition employee performance management policies are clear and concise in outlining its principles, processes and objectives. However, the extent to which these are followed differ between countries, managers and employees respectively within the organization (Saajida \& Ukpere, 2014). These altogether invoked the need for scientific knowledge to ascertain if perhaps there is a significant effect of the social correlates on employee performance in the public health facilities in the Kenyan context in order to fill in the existing gap in literature.

\subsection{Research Objectives}

The study was guided by the following general and specific objectives;

\subsubsection{General Objective}

To assess the effects of social correlates on employee performance in public health facilities in Turbo subcounty, Kenya

\subsubsection{Specific Objectives}

The study was guided by the following objectives;

1) To examine the effect of Supervisors support on employee performance in public health facilities in Turbo Sub-County, Kenya. 
2) To analyze the effect of employee participation on employee performance in public health facilities in Turbo Sub-County, Kenya.

\subsection{Research Hypotheses}

The study was guided by the following research hypothesis;

$\mathbf{H o}_{1}$ : Supervisors support does not significantly affect employee performance in public health facilities in Turbo Sub-County, Kenya.

$\mathrm{Ho}_{2}$ : Employee participation does not significantly affect employee performance in public health facilities in Turbo Sub-County, Kenya.

\section{Literature Review}

\section{Theoretical Framework}

The relationship between social correlates and employee performance is premised on Conservation of Resources Theory (COR) Hobfoll's $(1988,1998)$ and Social Exchange Theory Malinowski, 1922; Mauss, 1925.

\subsubsection{Social Exchange Theory (SET)}

Social Exchange Theory (SET) is among the most influential conceptual paradigms for understanding workplace behavior whose venerable roots can be traced back to at least the 1920 s by Malinowski, 1922; Mauss, 1925 (Cropanzano \& Mitchell, 2005). Social Exchange Theory posits that human relationships are formed by the use of a subjective cost-benefit analysis and the comparison of alternatives (Amir et al., 2016). Social Exchange Theory thus remains an instrumental model for interpreting society as a series of interactions between people that are based on estimates of rewards and punishments (Crossman, 2017). It can therefore be, argued that our interactions are determined by the rewards or punishments that we expect to receive from others, which we evaluate using a cost-benefit analysis model (whether consciously or subconsciously).

Reciprocity is ingrained in the SET as a cultural mandate, in which those who do not comply are punished. In fine those who receive the rewards must reciprocate in particular behavior. Individuals with a strong exchange orientation are more likely to return a good deed than those with low exchange orientation (Amir et al., 2016). Eisenberger et al. (2004) cited in Laura, Janaki and Michele (2015) argue that reciprocity represents quid pro quo propensities whether positive or negative.

\subsubsection{Conservation of Resources Theory (COR)}

Hobfoll's (1988, 1998) COR theory explains employees' motivation to accumulate, protect, expend, and replenish personally valued resources which are used to meet the demands of the work environment (Wheeler \& Jonathon, 2009). Resources are those entities that either are centrally valued in their own right (e.g. Self-esteem, close attachments, health, and inner peace) or act as a means to obtain centrally valued ends (e.g., money, social support, and credit) (Hobfoll, 2011). According to the COR model, individuals seek to acquire and maintain resources, including objects (e.g., homes, clothes, food), personal characteristics (e.g., self-esteem), conditions (e.g., being married or living with someone who provides social support, more financial security), and energies (e.g., time, money, and knowledge). Stress occurs when there is a loss of resources, or a threat of loss. For example, the model proposes that work-family conflict leads to stress because resources (e.g., time, energy) "are lost in the process of juggling both work and family roles", which in turn leads to job dissatisfaction, anxiety, and thoughts about quitting one's job. Individual difference variables, such as self-esteem, are treated as resources that may moderate the relationship between work-family conflict and stress (Selvarajan \& Barjinder, 2016). Based on Hobfoll's $(1989,1998)$ postulation employees not only invest current resources to gain future resources but also draw on available sources of social support (Wheeler \& Jonathon, 2009). This gives credence for the use of this theory in understanding social correlates and employee performance.

\subsubsection{Effect of Supervisors' Support on Employee Performance}

Supervisor support is defined as employees' views concerning the degree to which their supervisors value their contributions and care about their wellbeing (Chandrasekar et al., 2011). According to Sadiya and Maimuna (2015) it is the degree to which supervisors value the contributions of employees and care about their wellbeing. The responsibilities of supervisors are to delegate work, and to give information or advice to subordinates. In acknowledging that it is the duty of supervisors to ensure that employee job performance is at maximum potential, it would be advantageous for managers in all trades and industry sectors worldwide to understand what types of employee-supervisor interactions are associated with employee job performance (Kim, Hon \& Lee, 2010). Supervisor support leads to high employee commitment through job satisfaction and motivation.

Along with the increased emphasis on workplace learning, evidence also is accumulating that organizations are devolving human resource management responsibilities to supervisors and line managers in order to enhance employee performance (Sadiya, 2015). This decentralization of tasks broadens the core responsibilities of first line supervision from traditional duties of monitoring and administration to a set of performance oriented tasks that identify, assess, and 
develop the competencies of subordinates and align their performance with the strategic goals of the organization (Batia, 2016). Thus, our subject of study is the HR role of supervisors in skill development and performance improvement. One approach to performance improvement is for supervisors to provide individualized instruction and guidance to employees in the context of daily work. This activity is generally referred to as informal training, but it is more accurately described as coaching, which the literature defines as an unstructured, developmental process in which managers provide one on one feedback and guidance to employees in order to enhance their performance (Armstrong, 2010). However, supervisors may combine individualized coaching with other strategies to improve performance.

Although they have little control over such HR policies as recruitment, selection, or compensation, they have primary responsibility for coaching and managing the working relationships among employees in their work groups. They can, for example, create a work environment that enhances group processes of communication, motivates cooperation and learning Agarwal (2009) and reinforces their one on one coaching interactions with employees. We refer to practices that enhance working relationships among peers as "group management practices." Our assumption is that these practices may be effective for work that is individualized or loosely organized into group they do not depend on high levels of interdependence in teams (Batia, 2016).

HR literature has identified three dimensions of the $H R$ system that enhance performance: investment in training, work designed to allow employees to interact and develop their skills, problem solving abilities, and incentives to motivate effort (Agarwal, 2009). Although the HR literature has found significant relationships between these dimensions and performance at the organizational level Combs et al. (2006) some have called for studies that illuminate how these relationships are effectively implemented at lower levels of the organization (Westerm \& Simmons, 2007). We contribute to the HR literature by providing a context specific example of how supervisors implement these three dimensions of the HR system to improve employee performance. We contribute to the training literature by showing the link between coaching and other HR management activities that, taken together, should improve performance. This emphasis on management practices departs from the training literature, which often treats training as primary and other organizational factors as "context," or "environment." We theorize that supervisory variation in individual coaching and group management practices has both direct and synergistic effects on individual performance improvement. The synergies depend on whether these practices are congruent, or consistent, among themselves (Khan \& Habib, 2011).

However, despite the growing importance of supervisory support and commitment, relatively few studies have empirically investigated the consequences of this construct. The supervisor support is particularly important because supervisors are formally responsible for monitoring the performance of employees, are involved in decisions regarding pay and promotions that affect their employees and are increasingly made accountable for reducing turnover in their teams (Panaccio \& Vandenberghe, 2011). Previous studies have verified that when employees perceive a high level of support and assistance from their supervisor, such perception facilitates improving employees' attitude toward work, which encourages employee to devote greater effort to their work and in turn motivates employees to do things that are beyond the scope of their duties (Wanjau \& Kyongo, 2013). However there is a broad divergence in employee perceptions of supervisor supportiveness among different countries (Rucha, 2013). These did set the stage for hypothesizing on the effect of supervisors' support on employee performance.

\subsubsection{Effects of Employee Participation on Employee Performance}

There is increasing evidence indicating that employee participation enhances employee performance since it has the ability to improve quality decision making by raising the inputs (Francine, 2014). Employee performance improvement courtesy of worker participation ranges from improved quality as well as high productivity to lower scrap rates occasioning consumer satisfaction. Equally in a related study of 42 organizations by Pheko (2013) he noted that employee participation was directly related with enhanced employee performance and resulted in increased company productivity in the subsequent year.

The findings of Khattak, Igbal and Bashir (2012) also indicated that employee involvement and participation at work has significant positive effect on job satisfaction, leading to improved organizational performance. Ravenswood (2011) focused on SMEs and their findings showed that employee participation has positive impact on job satisfaction. Thornton (2009) established a significant relationship between frequency of employees' consultation and job satisfaction. Karinaand Raymond (2012) suggested that greater number of practices of employee's involvement and participation at work and more frequent of use of these practices ensures organizational commitment and job satisfaction among the employees. Despite the high profile of employee participation concepts in organizations recently, there have been many differing views and definitions of the subject.

According to Locke et al. (2015) employee participation is defined as a method that utilizes the capacity of the workforce and it is designed to enhance workers' commitment to the overall organization success. Another important definition was made by Chengedzai and Pooe (2013) who stated that employee participation 
can be described as the positive attitude that a worker has towards the values of an organization. Further, he stated that involved employees are of business context, and collaborate with colleagues to improve their employee performance within the job for the benefit of the organization. However Pheko (2013) defined employee participation in a more descriptive fashion by stating that employee participation as the process of enabling employees to participate in the critical thinking process that is intended at making decisions that affect the organization. Employee participation is an initiative that enables employee to partake in decision making and enhancement of activities convenient to their level in the organization. According to Chengedzai and Pooe (2013) employee participation include a variety of processes devised to enlist the comprehension and maximum contribution of employees in an organization and their commitment to its objectives which results in increase of organizational performance (Chengedzai \& Pooe, 2013).

Further Zhu et al.(2015) also contends that employee participation is a process involving participation, communication and decision making which leads to industrial democracy and employee motivation. Therefore employee participation has been conceptualized as a set of activities that enable workers to develop a feeling of ownership and responsibility towards the organization and it enables workers to take part in problem solving, decision making and information processing (Kassachoon \& Siminyu, 2014). Thus, employee participation harnesses the power of people in an organization and focuses it towards the achievement of strategic goals and objectives of the organization.

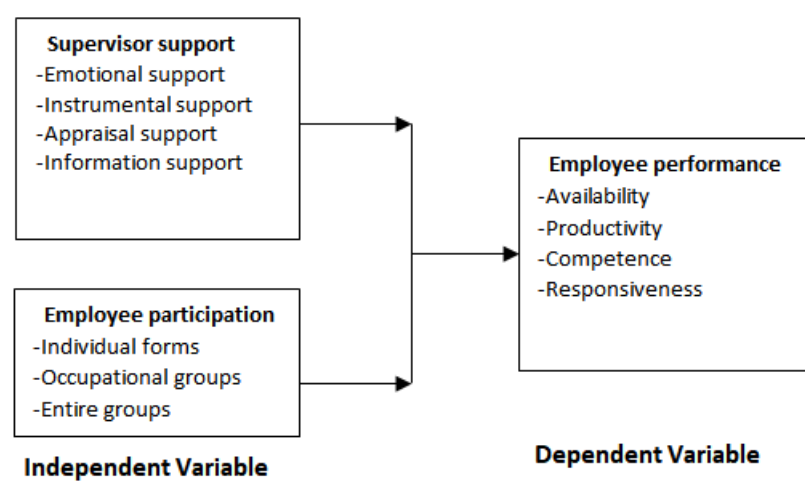

Therefore, it can be deduced that employee participation is a critical factor in the success and prosperity of any organization because employees are the organization greatest assets. Despite Siminyus' findings in 2014; where he only focused on how employee participation affects organizations' objectives, there is still the need to have this construct studied more but this time round linked to employee performance. This was just but the next horizon for this research which focused on three important dimensions of employee participation: The individuals, occupational groups and entire groups so as to ascertain how each affects employee performance in the long run.

\subsection{Research Gap}

Social correlates beget a positive interaction between organizational functions such as employees and stakeholders which eventually occasions high employee and organizational performance. Despite the extensive research on the relationship between social correlates and employee performance, several gaps in previous investigations can be identified. Majority of studies on employee performance have been conducted in the western nations which includes McGlynn, et al., 2003;Nelson, 2005;Beith, Eicher, and Weil, 2007;Asaad and Assaf, 2011, ;Ajay, Gangaram, and Beatty, 2016 ;Aliya, Maiya, Farah, and Hina, 2015; Batia, 2016 ;Batia, 2017; Sinokki, 2011; but the prevailing view is that the developing countries' cultural context is different from developed countries' western culture. On this note, western-derived and tested arguments cannot be used to explain and understand organizational problems in developing African countries. This is according to Blunt and Jones, (1992) cited in (Onyango, Otieno, Bii, \& Otieno, 2016). Besides Employee performance management policies are clear and concise in outlining its principles, processes and objectives, however, the extent to which these are followed differ between countries, managers and employees respectively within the organization (Saajida \& Ukpere, 2014).

Majority of studies have focused on employee performance but with different predictors other than social correlates such as supervisors support and employee participation as a bundle to find out how they jointly affect employee performance. This study assessed the effects of social factors of such as Supervisors Support, employee participation, knowledge sharing and procedural justice adopted from Schepers and van den Berg (2007) who only looked at how these factors affects employee satisfaction and not employee performance. On the same note, these social factors affecting employee performance differ in priority depending on the context (Marjolein \& Harnmeijer, 2006).

According to Locke et al., (2007) most of the researchers in the field of organizational justice did not take into account the context of social interaction where formal procedures and decisions are implemented. Rucha (2013) emphasized on the broad divergence in employee perceptions of supervisor supportiveness among different countries which sets the stage for hypothesizing on the effect of supervisor support on employee performance. Sentiments were echoed too by Angerer (2003) who raised a concern about researchers who only talked about necessities, benefits and the content of knowledge sharing but failed to point out the relationship between knowledge sharing and employee performance. This created knowledge gap and thus informed the adoption of knowledge sharing as one of the variables that affect employee performance. This study was a dispatch from Schepers and van den Berg (2007) study by looking at how social factors correlate employee performance in the 
public sector in the Kenyan context in order to fill in the existing gap in literature.

\section{Research Design and Methodology}

\subsection{Research Design}

The study adopted descriptive survey research, a scientific method which involves observing (surveying) and describing the behaviour of a subject without influencing it in any way (Saunders, Lewis \& Thornhill, 2007). According to Kothari and Garg (2014) Survey method is a popular and common strategy in business research. It enables large amount of data to be collected from an ideal population and in a highly economical way. Often, questionnaires are used and the data collected is standardized, easily understood and easy to compare. This method was beneficial in gaining a deeper understanding of the problems being investigated through different sources of information, as well as to be able to describe a general picture of the reliability in which the problem is involved (DeVaus, 2002). It is often characterized by the selection of random samples from large populations to obtain empirical knowledge of a contemporary nature (Saunders, Lewis \& Thornhill, 2007). The descriptive survey design was appropriate for the current study because it provided the researcher with the desired information and understanding of the relationship between social correlates and the employee performance in the public health sector.

\subsection{Population of the Study}

Population is defined as group from which information is sought. Target population is the entire group a researcher is interested in (Brannen \& Gemma, 2012). The accessible population of the study was 332respondents who were drawn from the following public health facilities: 34 Cheramei, 76 Huruma, 22 Osurungai, 26 Chepsaita, 26 Kiplombe, 35 Eldoret West, 34 Turbo, 28 Kapyemit, 26 Sambut and 25 Sosiani; public health facilities in Turbo Sub-County. The respondents were drawn from clinical and non-clinical staff.

Table3.1: Population of Study

\begin{tabular}{cccc}
\hline Clusters & Cadre of staff & Population of study & Percentage \\
\hline Cheramei & Clinical & 28 & 8.4 \\
& Non clinical & 6 & 1.8 \\
Huruma & Clinical & 52 & 15.7 \\
& Non clinical & 24 & 7.2 \\
Osurungai & Clinical & 16 & 4.8 \\
& Non clinical & 6 & 1.8 \\
Chepsaita & Clinical & 19 & 5.7 \\
& Non clinical & 7 & 2.2 \\
Kiplombe & Clinical & 18 & 5.4 \\
& Non clinical & 8 & 2.4 \\
Eldoret West & Clinical & 26 & 7.8 \\
& Non clinical & 9 & 2.7 \\
Turbo & clinical & 27 & 8.2 \\
& Non clinical & 7 & 2.2 \\
Kapyemit & Clinical & 22 & 6.6 \\
& Non clinical & 6 & 1.8 \\
Sambut & Clinical & 19 & 5.7 \\
& Non clinical & 7 & 2.1 \\
Sosiani & Clinical & 19 & 5.7 \\
Total & Non clinical & 6 & 1.8 \\
\hline & & 332 & $\mathbf{1 0 0}$ \\
\hline
\end{tabular}

\subsection{Sampling Technique and Sample Size}

A sample size refers to the number of people in the respondent group determined by the scope of the research and based on precision rate and confidence level (Collis \& Hussey, 2014). A sample frame is the group of individuals that can be selected from the target population given the sampling process used in the study and how they are accessed (Martínez-Mesa et al., 2016). In this study, the Sample frame consisted of both clinical and non-clinical staff from public health facilities in Turbo Sub-County. A two stage sampling technique was used to narrow down to the public health facilities. Cluster random sampling technique was used to select the public health facilities. Simple random sampling was used to select the respondents. This sampling technique aimed at selecting groups that displayed variation on a particular phenomenon (Collis \& Hussey, 2009).

In this case, the public health facilities served as clusters, from which random samples within these groups were selected. The size of each group was determined through proportional allocation. The method involves selecting at random from a list of the population (a sampling frame) the required number of participants (Martínez-Mesa et al., 2016). Therefore 181respondentswere selected for a sample for this study. 
A good maximum sample size is usually around $10 \%$ of the population (Bullen, 2016).The study used Krejcie \& Morgan table (1970) to calculate the sample size which was 181 as per the table.
Therefore 181 which is $54.5 \%$ of the population was preferable. The sample proportions from each public health facility were determined using the formula below:

$n_{i}=\left(N_{i} X n\right) / N$

Table 3.2: Sample Size

\begin{tabular}{|c|c|c|c|}
\hline Clusters & Cadre of staff & Population of study & $n_{i}=\left(N_{i} X n\right) / N$ \\
\hline \multirow{2}{*}{ Cheramei } & Clinical & 28 & 15 \\
\hline & Non clinical & 6 & 3 \\
\hline \multirow{2}{*}{ Huruma } & Clinical & 52 & 29 \\
\hline & Non clinical & 24 & 13 \\
\hline \multirow{2}{*}{ Osurungai } & Clinical & 16 & 9 \\
\hline & Non clinical & 6 & 3 \\
\hline \multirow{2}{*}{ Chepsaita } & Clinical & 19 & 10 \\
\hline & Non clinical & 7 & 4 \\
\hline \multirow{2}{*}{ Kiplombe } & Clinical & 18 & 10 \\
\hline & Non clinical & 8 & 4 \\
\hline \multirow{2}{*}{ Eldoret West } & Clinical & 26 & 14 \\
\hline & Non clinical & 9 & 5 \\
\hline \multirow{2}{*}{ Turbo } & clinical & 27 & 15 \\
\hline & Non clinical & 7 & 4 \\
\hline \multirow{2}{*}{ Kapyemit } & clinical & 22 & 13 \\
\hline & Non clinical & 6 & 3 \\
\hline \multirow{2}{*}{ Sambut } & Clinical & 19 & 10 \\
\hline & Non clinical & 7 & 4 \\
\hline \multirow{2}{*}{ Sosiani } & Clinical & 19 & 10 \\
\hline & Non clinical & 6 & 3 \\
\hline Total & & 332 & 181 \\
\hline
\end{tabular}

\subsection{Data Collection Instruments}

Collis and Hussey (2014) noted that the research instruments are the means by which primary data can be collected and have the advantage of ensuring that more data is obtained. The study used questionnaires as well as reviewing existing literature. These instruments supplemented each other and gave a deeper and wider exploration to research perspective.

\subsection{Pre-testing of Research Instruments}

Pre-testing refers to a study conducted before main study in order to test validity of the research instruments (Sreevidya \& Sunitha, 2011). Pre-testingof the questionnaire was done in Uasin Gishu District Hospital in order to identify whether the developed instrument was in agreement with the contents of the research questions. This enabled the researcher to affirm the validity of the sample participants as well as that of the content of the questionnaire. It also ensured that the questionnaire provided insight to the phenomenon being studied. Importantly, it enabled researcher to reconstruct some of the wordings of the questions before the actual research. It involved $10 \%$ of the size of the sample population (Kothari \& Garg, 2014). This means that 18 respondents drawn from sample population participated in the pretesting of the data instrument but did not take part in final study.

\subsubsection{Validity of Instruments}

Validity is described as the extent to which the research findings accurately reflect the phenomena under study (Collis \& Hussey, 2014). The internal validity was used to show to what extent the collection, analysis and interpretation of data relates with the research variables. The content validity was achieved by ensuring relevance of the research results with theoretical approaches and literature reviews (duPlooy \& Viktor, 2002). To ensure content validity, the researcher reviewed the literature in order to identify the items that required measuring the constructs, for example, Supervisors support, employee participation. Validity was also achieved by making sure that all the study constructs are captured in the questionnaires. Careful sampling of items ensured their representativeness.

\subsubsection{Reliability of Instruments}

In this study, reliability was determined by use of internal consistency technique. The rationale for internal consistency is that the individual items should all be measuring the same constructs and thus correlates positively to one another. Internal consistency was measured through Cronbach's alpha coefficient. The test of reliability was calculated using the SPSS (Statistical Package for Social Science Version 20). The Cronbach's alpha coefficient (DeVaus, 2002)was used to calculate for reliability. As a rule of thumb, the acceptable alpha is at 
least 0.70 or above (DeVaus, 2002; Hair, Money, Page, \& Samouel, 2007).

\subsection{Data Processing and Analysis}

Data was analyzed using descriptive (mean, standard deviation, frequencies, skewness and kurtosis) and inferential statistical techniques. Under inferential statistics, multiple regressions was used to determine the effect of a set of independent variable (social correlates) on dependent variable (employee performance), coefficient of correlation using the Statistical Package for Social Sciences (SPSS) version 20.0package.

The regression model was as follows:

$$
y=\beta 0+\beta_{1} X_{1}+\beta_{2} X_{2}+\varepsilon
$$

Where $Y$ was employee performance, dependent variablexwas social correlates, 6 was the standardized regression coefficient.

$X_{1}$ represent Supervisors support

$\mathrm{X}_{2}$ represent Employee participation

\section{Data Analysis, Results Findings and Discussion}

\subsection{Descriptive Statistics for the Variables}

The findings from the study were analyzed using descriptive statistics, which included means and standard deviations. Means and standard deviations for the independent and dependent variables were computed from the respondents' responses. The purpose of means and standard deviations was to provide a general picture of how the respondents perceived the effects of social correlates on employee performance in public health facilities in Turbo Sub- County. Skewness and Kurtosis was used to test for the assumption of normality.

\subsubsection{Descriptive Statistics for Supervisors Support on Employee Performance}

The researcher sought to establish the level of agreement to various aspects of supervisors support as per objective one. Five response items were used to examine the prevailing status of supervisors support.

Table 4.2: Supervisors Support Descriptive Statistics

\begin{tabular}{|c|c|c|c|c|c|c|c|}
\hline Responses & SD \% & $\mathrm{D} \%$ & UD\% & $\mathrm{A} \%$ & SA\% & MEAN & SD \\
\hline $\begin{array}{c}\text { The supervisor acts as counselor hence providing } \\
\text { emotional support. }\end{array}$ & 0 & 6 & 10.3 & 33.9 & 55.2 & 4.44 & .740 \\
\hline $\begin{array}{l}\text { The supervisor acts as counselor hence providing } \\
\text { emotional support. }\end{array}$ & 0 & 1.9 & 21.8 & 31.5 & 44.8 & 4.19 & .710 \\
\hline $\begin{array}{c}\text { Appraisal of work is objectively done to all } \\
\text { employees. }\end{array}$ & 0 & 6.1 & 23.6 & 35.8 & 34.5 & 3.99 & .911 \\
\hline Appraisal feedback is given to employees on time. & 0 & .6 & 27.9 & 30.3 & 41.2 & 4.12 & .839 \\
\hline $\begin{array}{c}\text { Supervisor shares meaningful information } \\
\text { concerning work. }\end{array}$ & 0 & 2.4 & 27.9 & 50.9 & 18.8 & 3.86 & .740 \\
\hline
\end{tabular}

According to the findings presented in Table $4.2,89.1 \%$ of the respondents agreed and strongly agreed that supervisor acts as counselor hence providing emotional support $(M=4.44 \mathrm{SD}=0.740), .6 \%$ were in disagreement and $10.3 \%$ were undecided. $76.3 \%$ of the respondents both agreed and strongly agreed that supervisor provides necessary instruments for work ( $M=4.19 \mathrm{SD}=.710)$ while $1.9 \%$ and $21.8 \%$ were in disagreement and undecided respectively. Besides, a majority of the employees both agreed and strongly agreed (70.3\%) that appraisal of work was objectively done to all employees ( $M=3.99$ $\mathrm{SD}=0.911), 6.1 \%$ disagreed while $23.6 \%$ were undecided $71.5 \%$ of the respondents were in agreement that appraisal feedback is given to employees on time ( $M=4.12$ $\mathrm{SD}=0.839$ ), $0.6 \%$ disagreed while $27.9 \%$ undecided. Lastly $69.7 \%$ respondents agreed and strongly agreed that supervisor shares meaningful information concerning work ( $M=3.86 \mathrm{SD}=.740$ ), $2.4 \%$ disagreed while $27.9 \%$ were undecided.

The implications of these results is that the public health facilities should embrace supervisors support so as to acquire better performance results. This was affirmed by the responses from the interviews with the facility in charges who reported that their facilities provided the necessary support to their staffs. They confirmed that they offered emotional, instrumental, appraisal and informational support. However the majority of interviewees lamented inefficiency and inadequacy of counseling services within the work place owing to fear of dual relationship amongst the staff hence compromising on emotional support. This argument is supported by the fact that dual relations between the staff and the supervisor certainly pose several ethical concerns and challenges for every-day practice such as ensuring confidentiality, or maintaining a professional distance thus affecting the efficiency of emotional support (Burgard, 2013). Supervisor support plays a substantial role in increasing employee job satisfaction (Muhammad, Muhammad, Anum \& Samina, 2017).

\subsubsection{Descriptive Statistics for Employee Participation on Employee Performance}

Research objective two sought to establish the effect of employee participation on performance of employees in 
public health facilities in Turbo Sub County. The study conceptualized that employee participation had an effect on employee performance. Thus; five questionnaire items were used to examine the prevailing status of employee participation in the public health facilities in Turbo Sub County. Results presented in Table 4.3 reveal that a total of $74 \%$ of the respondents both agreed and strongly agreed that employees participate at personal level in organizational activities ( $M=3.90 \mathrm{SD}=1.045), 13.3 \%$ were in disagreement while $12.7 \%$ were undecided. Besides, a majority of the employees $66.1 \%$ of the respondents agree that departments participate in decision making on issues affecting their occupational roles $(M=3.85$ $\mathrm{SD}=1.322$ ), $24.2 \%$ were in disagreement while undecided were $9.7 \%$. A total of $70.9 \%$ of the respondents also agreed and strongly agreed that there is always a consultative meeting where all employees are involved ( $\mathrm{M}=4.11 \mathrm{SD}=.988), 7.3 \%$ disagreed and strongly disagreed while $21.8 \%$ were undecided. A total of $66.7 \%$ of respondents agreed and strongly agreed that employees are involved in setting performance targets, $(M=3.96$ $\mathrm{SD}=1.050), 7.2 \%$ strongly disagreed and disagreed while $26.1 \%$ were undecided. Lastly $77.5 \%$ of the respondents agreed and strongly agreed that employees are encouraged to fully participate in decisions affecting their welfare $(M=4.07 \mathrm{SD}=.856), 5.5 \%$ were in disagreement while $17.0 \%$ were undecided. From the interviews with the facility in charges, the common response was that employees have limited scope in terms of entire group participation owing to diversity of their professional demands. Besides, certain decisions are influenced by professional bodies hence limiting the scope of participation. The facilities offers room for individual participation but this is within the confines of the regulation of professional roles. The implication of this is that there should be policy frameworks which recognize and influence employee participation within various domains of their work.

Table 4.3: Employee Participation Descriptive Statistics

\begin{tabular}{|c|c|c|c|c|c|c|c|}
\hline Responses & SD \% & D\% & UD\% & A\% & SA\% & MEAN & SD \\
\hline $\begin{array}{c}\text { Employees participate at personal level in } \\
\text { organizational activities }\end{array}$ & 2.4 & 10.9 & 12.7 & 42.0 & 32.0 & 3.90 & 1.045 \\
\hline $\begin{array}{l}\text { Departments participate in decision making on } \\
\text { issues affecting their occupational roles. }\end{array}$ & 4.2 & 20.0 & 9.7 & 18.2 & 47.9 & 3.85 & 1.322 \\
\hline $\begin{array}{l}\text { There is always a consultative meeting where all } \\
\text { employees are involved. }\end{array}$ & 0 & 7.3 & 21.8 & 23.6 & 47.3 & 4.11 & .988 \\
\hline $\begin{array}{c}\text { Employees are involved in setting performance } \\
\text { targets. }\end{array}$ & 3.0 & 4.2 & 26.1 & 27.3 & 39.4 & 3.96 & 1.050 \\
\hline $\begin{array}{l}\text { Employees are encouraged to fully participate in } \\
\text { decisions affecting their welfare. }\end{array}$ & 0 & 5.5 & 17.0 & 43.0 & 34.5 & 4.70 & .856 \\
\hline
\end{tabular}

Table 4.6: Employee Performance Descriptive Statistics

\begin{tabular}{|c|c|c|c|c|c|c|c|}
\hline Responses & SD \% & $\mathrm{D} \%$ & UD\% & $\mathrm{A} \%$ & SA\% & MEAN & SD \\
\hline I am encouraged to arrive on time at work. & 0.7 & 4.6 & 4.4 & 47.3 & 43.0 & 4.33 & .664 \\
\hline I am motivated to meet my work deadlines & 0.0 & 1.5 & 6.3 & 45.5 & 46.7 & 4.38 & .648 \\
\hline $\begin{array}{l}\text { I am expected to use my skills, abilities } \\
\text { knowledge to work independently. }\end{array}$ & 9.1 & 0.6 & 5.5 & 30.3 & 54.5 & 4.39 & .754 \\
\hline $\begin{array}{c}\text { Efficient service delivery to clients is always } \\
\text { encouraged. }\end{array}$ & 6.1 & 4.0 & 12.4 & 34.5 & 43.0 & 4.21 & .785 \\
\hline I easily adapt to change at my workplace. & 4.0 & 0.6 & 16.6 & 29.7 & 49.1 & 4.27 & .807 \\
\hline
\end{tabular}

\subsubsection{Descriptive Statistics for Employee Performance} Variable

The dependent variable of the study was employee performance. The study conceptualized that social correlates could have an effect on employee performance. To this end, five questionnaire items were used to assess employee performance in public health facilities in Turbo Sub County. Results displayed in Table 4.6, reveals that $90.3 \%$ of respondents concurred that they are encouraged to arrive on time at work ( $M=4.33$ $\mathrm{SD}=.664$ ) while $5.3 \%$ were in disagreement. $92.2 \%$ of the respondents were of the view that they were motivated to meet my work deadlines. ( $M=4.38 \mathrm{SD}=.648), 1.5 \%$ were in disagreement while $6.3 \%$ were undecided. $84.4 \%$ of the respondents were also in agreement that they are expected to use their skills, abilities knowledge to work independently $(M=4.39 S D=.754), 9.7 \%$ were in a disagreement while $5.5 \%$ were undecided. $77.5 \%$ of the respondents agreed that they efficiently deliver services to clients. ( $M=4.21 \mathrm{SD}=.785), 10.1 \%$ were in disagreement while $16.6 \%$ were undecided.78.8\% of the respondents also agreed that they easily adapt to change at their workplace $(\mathrm{M}=4.27 \mathrm{SD}=.807)$ while $4.6 \%$ were in disagreement. According to the interview responses, majority noted that the performance ratings of their staffs is normally as per customer expectations due to performance contracting and that most of the staffs always arrived to work on time, met work deadlines and were ready to adopt to change at the workplace. 


\subsubsection{Assumption of Linearity}

Table 4.8: Test for Linearity

\begin{tabular}{cccc}
\hline & $\begin{array}{c}\text { Supervisors } \\
\text { Support }\end{array}$ & $\begin{array}{c}\text { Employee } \\
\text { Participation }\end{array}$ & $\begin{array}{c}\text { Employee } \\
\text { performance }\end{array}$ \\
\hline $\begin{array}{c}\text { Supervisors } \\
\text { support }\end{array}$ & 1 & & \\
$\begin{array}{c}\text { Employee } \\
\text { Participation }\end{array}$ & $.294^{*}$ & 1 & 1 \\
Employee & $.660^{*}$ & $.450^{*}$ & 1 \\
performance & & & \\
\hline
\end{tabular}

"Correlation is significant at the 0.05 level (2-tailed).

Pearson's correlation coefficients were used to test linearity assumption. The purpose of using correlation was to identify social correlates that provide best predictions for conducting regression analysis. The intercorrelations among the variables are shown in Table 4.8. From the results, it can be seen that correlations among the social correlates were significant. Correlations between supervisors support, employee participation where $r=.660^{*}, r=.450^{*}$, respectively were also positively and significantly related to employee performance where
$P<0.05$. Linearity assumption was therefore satisfied. This implies that all the social correlates under study jointly have a positive and significant impact on employee performance in public health facilities in Turbo Sub County as such it behooves the management of the public health sector to pay high premiums on these social correlates to secure high employee performance.

\subsection{Regression Analysis}

\subsubsection{Effects of Supervisors Support on Employee Performance}

The model summary presented in table 4.9 involves supervisors support as the only independent variable. The coefficient of determination ( $R$ square) of 0.603 indicated that the model explained only $60.3 \%$ of the variation or change in the dependent variable with the remainder of $39.7 \%$ explained by other factors other than supervisors support. Adjustment of the $\mathrm{R}$ square did not change the results substantially, having reduced the explanatory behavior of the predictor to $60.3 \%$

Table 4.9: Model Summary

\begin{tabular}{|c|c|c|c|c|c|}
\hline 1 & $.778^{\mathrm{a}}$ & .605 & .603 & .328 & 1.736 \\
\hline
\end{tabular}

Table 4.10 ANOVA $^{\mathrm{a}}$

\begin{tabular}{clccccc}
\hline & Model & Sum of Squares & Df & Mean Square & F & Sig. \\
\hline \multirow{2}{*}{1} & Regression & 26.889 & 1 & 26.889 & 250.120 & $.000^{\mathrm{b}}$ \\
& Residual & 17.523 & 163 & .108 & \\
& Total & 44.412 & 164 & & \\
\hline
\end{tabular}

a. Dependent Variable: Employee performance

b. Predictors: (Constant), Supervisors support

Second, the ANOVA output was examined to check whether the proposed model was viable. Results shown in Table 4.10 reveal that the F-statistic was highly significant $(F=250.120 p<0.05)$, this shows that the model was valid.

The model significantly improved the ability to predict employee performance. Thus, the model was significant.

\subsubsection{Regression Coefficients of Employee Performance}

Results of the regression coefficients presented in Table 4.11 shows that the estimates of $\beta$ values and give an individual contribution of a predictor to the model. The $\beta$ value tells us about the relationship between employee performances with each predictor. The positive $\beta$ value indicates a positive relationship between the predictors and the outcome. The $\beta$ value for supervisors support (.778) was positive. The positive $\beta$ values indicate the direction of relationship between predictor and outcome. From the results (Table 4.11) the model was then specified as:

$$
y=B_{1} X_{1}+\varepsilon
$$

Employee performance $=.778$ supervisors support $+\varepsilon$

The coefficient of the variable indicates the amount of change one could expect in employee performance given a one-unit change in the value of that variable, given that all the variables in the model are standardized basing on the standardized coefficients. Result reveal standardized regression coefficient for supervisors support $(\beta=0.778)$, implies that an increase of 1 standard deviation in supervisors support is likely to result in a 0.778 standard deviations increase in employee performance. T-test was used to identify whether the predictor was making a significant contribution to the model. When the t-test associated with $\beta$ value is significant then the predictor is making a significant contribution to the model. The results show that supervisors support $(\mathrm{t}=15.815, \mathrm{P}<.05)$, 
Table 4.11: Regression Coefficients ${ }^{a}$

\begin{tabular}{|c|c|c|c|c|c|c|c|}
\hline \multirow{2}{*}{ Model } & \multicolumn{2}{|c|}{ Unstandardized Coefficients } & \multirow{2}{*}{$\begin{array}{l}\text { Standardized } \\
\text { Coefficients } \\
\text { Beta }\end{array}$} & \multirow{2}{*}{$\mathrm{t}$} & \multirow{2}{*}{ Sig. } & \multicolumn{2}{|c|}{ Collinearity Statistics } \\
\hline & B & Std. Error & & & & Tolerance & VIF \\
\hline (Constant) & 1.344 & .190 & & 7.089 & .000 & & \\
\hline${ }^{1}$ Supervisors support & .718 & .045 & .778 & 15.815 & .000 & 1.000 & 1.000 \\
\hline
\end{tabular}

Table 4.12: Model Summary

\begin{tabular}{|c|c|c|c|c|c|}
\hline Model & $\mathrm{R}$ & R Square & Adjusted R Square & Std. Error of the Estimate & Durbin-Watson \\
\hline 1 & $.473^{\mathrm{a}}$ & .224 & .219 & .460 & 1.421 \\
\hline
\end{tabular}

Table 4.13 ANOVA $^{\mathrm{a}}$

\begin{tabular}{|c|c|c|c|c|c|c|}
\hline & Model & Sum of Squares & Df & Mean Square & $\mathrm{F}$ & Sig. \\
\hline \multirow{3}{*}{1} & Regression & 9.930 & 1 & 9.930 & 46.940 & $.000^{b}$ \\
\hline & Residual & 34.482 & 163 & .212 & & \\
\hline & Total & 44.412 & 164 & & & \\
\hline
\end{tabular}

Table 4.14: Regression Coefficients ${ }^{a}$

\begin{tabular}{|c|c|c|c|c|c|c|c|c|}
\hline & \multirow[t]{2}{*}{ Model } & \multicolumn{2}{|c|}{ Unstandardized Coefficients } & \multirow{2}{*}{$\begin{array}{c}\text { Standardized } \\
\text { Coefficients } \\
\text { Beta }\end{array}$} & \multirow[t]{2}{*}{$\mathrm{t}$} & \multirow[t]{2}{*}{ Sig. } & \multicolumn{2}{|c|}{ Collinearity Statistics } \\
\hline & & B & Std. Error & & & & Tolerance & VIF \\
\hline \multirow[b]{2}{*}{1} & (Constant) & 2.604 & .252 & & 10.320 & .000 & & \\
\hline & $\begin{array}{c}\text { Employee } \\
\text { participation }\end{array}$ & .430 & .063 & .473 & 6.851 & .000 & 1.000 & 1.000 \\
\hline
\end{tabular}

\subsubsection{Effects of Employee Participation on Employee Performance}

The model summary presented in table 4.12 involves employee participation as the only independent variable. The coefficient of determination ( $R$ square) of 0.219 indicated that the model explained only $21.9 \%$ of the variation or change in the dependent variable with the remainder of $78.1 \%$ explained by other factors other than employee participation. Adjustment of the $\mathrm{R}$ square did not change the results substantially, having reduced the explanatory behavior of the predictor to $21.9 \%$.

Second, the ANOVA output was examined to check whether the proposed model was viable. Results shown in Table 4.13 reveal that the F-statistic was highly significant $(F=46.940 p<0.05)$, this shows that the model was valid.

The model significantly improved the ability to predict employee performance. Thus, the model was significant.

\subsubsection{Regression Coefficients of Employee Performance}

Results of the regression coefficients presented in Table 4.14 shows that the estimates of $\beta$ values and give an individual contribution of a predictor to the model. The $\beta$ value tells us about the relationship between employee performances with each predictor. The positive $\beta$ value indicates the positive relationship between the predictors and the outcome. The $\beta$ value for employee participation (.473) was positive. The positive $\beta$ values indicate the direction of relationship between predictor and outcome. From the results (Table 4.14) the model was then specified as:

$y=B_{1} X_{1}+\varepsilon$

Employee performance $=.473$ Employee participation $+\varepsilon$ The coefficient of the variable indicates the amount of change one could expect in employee performance given a one-unit change in the value of that variable, given that all the variables in the model are standardized basing on the standardized coefficients. Result reveal standardized regression coefficient for employee participation $(\beta=0.473)$, implies that an increase of 1 standard deviation in employee participation is likely to result in a 0.473 standard deviation increase in employee performance. T-test was used to identify whether the predictor was making a significant contribution to the model. When the t-test associated with $\beta$ value is significant then the predictor is making a significant contribution to the model. The results show that employee participation ( $t=10.320, P<.05)$, 
Table 4.21 Model Summary

\begin{tabular}{|c|c|c|c|c|c|c|}
\hline Model & $\mathrm{R}$ & R Square & $\begin{array}{c}\text { Adjusted R } \\
\text { Square }\end{array}$ & $\begin{array}{c}\text { Std. Error of the } \\
\text { Estimate }\end{array}$ & $\begin{array}{l}\text { R Square } \\
\text { Change }\end{array}$ & Durbin Watson \\
\hline 1 & $.717^{\mathrm{a}}$ & .514 & .508 & .365 & .514 & 1.643 \\
\hline
\end{tabular}

Table 4.22: ANOVA

\begin{tabular}{ccccc}
\hline Sum of Squares & Df & Mean Square & F & Sig. \\
\hline 22.846 & 2 & 11.423 & 85.806 & $.000^{\mathrm{a}}$ \\
27.566 & 162 & .133 & & \\
44.412 & 164 & & & \\
\hline
\end{tabular}

a. Predictors: (Constant) Supervisors support, ,Employee participation

b. Dependent Variable: Employee Performance

Table 4.23: Regression Coefficients ${ }^{\mathrm{a}}$

\begin{tabular}{|c|c|c|c|c|c|c|c|c|}
\hline \multirow{2}{*}{\multicolumn{2}{|c|}{ Model }} & \multicolumn{2}{|c|}{ Unstandardized Coefficients } & \multirow{2}{*}{$\begin{array}{c}\text { Standardized } \\
\text { Coefficients } \\
\text { Beta }\end{array}$} & \multirow[t]{2}{*}{$\mathrm{t}$} & \multirow{2}{*}{ Sig. } & \multicolumn{2}{|c|}{ Collinearity Statistics } \\
\hline & & $\mathrm{B}$ & Std. Error & & & & Tolerance & VIF \\
\hline \multirow{3}{*}{1} & (Constant) & 1.720 & .210 & & 7.974 & .033 & & \\
\hline & Supervisors support & .431 & .042 & .584 & 10.197 & .000 & .913 & 1.095 \\
\hline & $\begin{array}{l}\text { Employee } \\
\text { participation }\end{array}$ & .243 & .050 & .278 & 4.859 & .041 & .913 & 1.095 \\
\hline
\end{tabular}

a. Dependent Variable: Employee Performance

\subsubsection{Effects of Social Correlates on Employee $\mathbf{y}=\boldsymbol{B}_{1} \boldsymbol{X}_{\mathbf{1}}+\boldsymbol{B}_{\mathbf{2}} \boldsymbol{X}_{\mathbf{2}}+\boldsymbol{\varepsilon}$}

Performance

Multiple regression analysis was used to test the formulated hypotheses. First, the model summary was analyzed to establish the strength of the conceptualized social correlates in predicting employee performance. Results presented in Table 4.21 reveals that the four constructs namely Supervisors support and employee participation, $51.4 \%$ of the variation in employee performance (Adjusted R Square $=0.514$ ). Therefore, the remaining $28.6 \%$ is explained by other factors not considered in the study.

Second, the ANOVA output was examined to check whether the proposed model was viable. Results shown in Table 4.22 reveal that the F-statistic was highly significant $(F=85.806 p<0.01)$, this shows that the model was valid.

The model significantly improved the ability to predict employee performance. Thus, the model was significant.

\subsubsection{Regression Coefficients of Employee Performance}

Results of the regression coefficients presented in Table 4.23 shows that the estimates of $\beta$ values and give an individual contribution of each predictor jointly to the model. The $\beta$ value tells us about the relationship between employee performance with each predictor. The positive $\beta$ values indicate the positive relationship between the predictors and the outcome. The $\beta$ value for Supervisors support (.584), Employee participation (.278). The positive $\beta$ values indicate the direction of relationship between predictors and outcome. From the results (Table 4.23) the model was then specified as:
Employee performance $=.584$ Supervisors support +.278 Employee participation $+\varepsilon$

The coefficients for each of the variables indicates the amount of change one could expect in employee performance given a one-unit change in the value of that variable, given that all the variables in the model are standardized basing on the standardized coefficients. Results reveal standardized regression coefficient for Supervisors support $\beta=.584$ implies that an increase of 1 standard deviation in Supervisors support is likely to result in a 0.584 standard deviations increase in employee performance. Standardized regression coefficient for Employee participation $\beta=.278$, implies that an increase of 1 standard deviation in Employee participation is likely to result in a 0.278 standard deviations increase in employee performance.

\subsection{Hypothesis Testing}

$\mathbf{H o}_{1}$ : Supervisors support does not significantly affect employee performance in public health facilities in Turbo Sub County, Kenya. From the regression analysis table $t$ value is $=10.197$ Similarly, $P$ value is equal to 0.000 that is less than 0.05.Table 4.24 is sufficient to show relative importance. Therefore, it is evident from the results that null hypothesis is rejected and alternate hypotheses are accepted as Supervisors support significantly affect employee performance. This implies that organizations should be strongly committed to supervisor support practices because this can foster employee satisfaction 
and secure greater employee commitment which can warrant an increase in employee performance. This finding is further corroborated by Wanjau and Kyongo (2013) who argued that when employees perceive a high level of support and assistance from their supervisor, such perception facilitates improving employees' attitude toward work, which encourages employee to devote greater effort to their work and in turn motivates employees to do things that are beyond the scope of their duties. This finding is also underpinned by Social Exchange theory which calls for cultural mandate, in which those who receive the rewards or any support from the supervisor must reciprocate in particular behavior.

$\mathbf{H o}_{2}$ : Employee participation does not significantly affect employee performance in public health facilities in Turbo Sub County, Kenya. Hypothesis two postulated a lack of significant effect of employee participation on employee performance. Standardized regression weight was found to be positive and explores that a positive relation is caused by independent variable in dependent variable. The value of $t$ value is $=4.859 p<0.05$ which is significant. Therefore, these results are providing sufficient ground for rejection of null hypotheses and accepting alternate hypotheses. In fine these results confirms that employee participation has a significant effect on employee performance. This implies that organizations should offer more active support for their employees' participation which is geared towards performance improvements linked to worker participation in improving quality as well as higher productivity in order to realize maximal employee performance. This finding is supported by the argument of inputs by Francine (2014) that increasing evidence indicating that employee participation enhances employee performance since it has the ability to improve quality decision making by raising the inputs (Francine, 2014).These findings and arguments submits to the Conservation of Resources Theory (COR) which explains that employee motivation helps to meet the demands of both work and non-work contexts as a function of resource protection, replenishment, and investment whose outcomes are of interest, including job performance, job satisfaction, organizational commitment, and turnover.

Table 4.24: Summary for Hypothesis Testing

\begin{tabular}{|c|c|c|}
\hline Hypothesis & $t$ and $P$ values & Decision \\
\hline $\begin{array}{l}\text { Ho }_{1} \text { : Supervisors support does not significantly affect employee performance in } \\
\text { public health facilities in Turbo Sub County, Kenya. }\end{array}$ & $\mathrm{t}=10.197, \mathrm{P}<0.05$ & Reject $\mathrm{Ho}_{1}$ \\
\hline $\begin{array}{l}\text { Ho }_{2} \text { : Employee participation does not significantly affect employee performance in } \\
\text { public health facilities in Turbo Sub County, Kenya. }\end{array}$ & $t=4.859, P<0.05$ & Reject $\mathrm{Ho}_{2}$ \\
\hline
\end{tabular}

\subsection{Discussion of Results}

The main purpose of the study was to assess the effects of social correlates on employee performance in public health facilities, Turbo Sub -County, Kenya. From the results, there is no second opinion to the fact that social correlates affect the performance of employees in public health facilities. In fact, organizations can only attain high employee performance by improving the psychosocial aspects of work environment which include psychological and social characteristics of work tasks and more general organizational environment where work is carried out. This fact is underpinned by the findings of this study.

The first objective was to examine the effect of Supervisors support on employee performance in public health facilities in Turbo Sub-County, Kenya. In acknowledging that it is the duty of supervisors to ensure that employee job performance is at maximum potential, it would be advantageous for managers in all trades and industry sectors worldwide to understand what types of employee-supervisor interactions are associated with employee job performance (Conway, 2018). Multiple regression analysis showed that a significant relationship exists between dependent variable and independent variables. The model explained only $60.3 \%$ of the variation or change in employee performance variable with the remainder of $39.7 \%$ explained by other factors other than supervisors support. From the regression analysis table $t$ value is $=10.197$ Similarly, $P$ value is equal to 0.000 that is less than 0.05 that is sufficient to show relative importance $r=.660^{*}$. Therefore, it is evident from the results that supervisors support was found to be a positive and a significant predictor of employee performance. This finding supports the findings of (Liu \& Batt, 2010;Ali\& Maimunah., 2016) who found a significant relationship between supervisors support and employee performance. They added that how supervisors manage their work groups has a direct impact on individual performance, with the use of team activities and group incentives associated with significantly higher individual performance. Lack of trust between supervisors and employees is an impediment to employee performance, and consequentially results in losses for the company in the form of wasted employee time (Conway, 2018). This implies that public health facilities in Turbo Sub-County should be strongly committed to supervisors support as this can help foster high employee performance which includes work place learning and development of competencies amongst the human resource and aligning their performance to strategic goals of the organization. It therefore behooves the supervisors to remain supportive, friendly and considerate, consult subordinates and recognize their contribution to engender satisfaction and high performance. 
The second objective of the study was to analyze the effect of employee participation on employee performance in public health facilities in Turbo SubCounty, Kenya. Pheko (2013) noted that employee participation is directly related with enhanced employee performance and resulted in increased company productivity in the subsequent year. This argument is justified by the findings of this study. Standardized regression weight was found to be positive and explores that a positive relation is caused by independent variable in dependent variable.

The model explained only $21.9 \%$ of the variation or change in employee performance variable with the remainder of $78.1 \%$ explained by other factors other than employee participation. The $t$ value $=10.320 \mathrm{p}<0.05$ $r=.473^{*}$ which is significant. Therefore, these results are providing sufficient ground to affirm that employee participation has a significant effect on employee performance in the public health facilities in Turbo SubCounty. In this regard consultative meeting in which employees are involved in setting performance targets and making decisions on issues affecting them would hold supreme in engendering maximal employee performance. These findings support the argument of (Wood \& de Menezes, 2011; Nuzhath, 2014) that there is greater significant link between employee participation in decision making and their performance towards the organization. This implies that the public health facilities should enhance participation of their employees in decision making which may lead to commitment, pooling of ideas, loyalty citizenship and trust towards the organization.

Result of multiple regressions further revealed that social correlates jointly and independently influence employee performance in public health facilities in Turbo Sub-County, Kenya. Jointly reveal that the four constructs namely supervisors support, employee participation, knowledge sharing, and procedural justice $51.4 \%$ of the variation in employee performance (Adjusted $\mathrm{R}$ Square = 0.514).Therefore, the remaining $48.6 \%$ is explained by other factors not considered in the study. As evident from the results displayed, amongst the social correlates, the most important predictor with respect to employee performance in the in public health facilities in Turbo SubCounty, Kenya was supervisors support, with $(\beta=$ $.584, t=10.197 \mathrm{P}=0.00)$.

This suggests that in the light of social correlates, supervisors support as a concept, when embraced by the public health facilities will contribute extensively to improving employee performance as compared to employee participation on employee performance. However the synergistic effect of the social correlates understudy cannot gainsaid. This implies that the management of public health facilities should pay high premiums in strategically formulating and implementing social correlates which can effectively galvanize employee motivation and performance.

\section{Conclusions and Recommendations}

\subsection{Conclusions}

From the findings, this study makes a number of conclusions. The study explored the relationship between the social correlates constructs such as: supervisors support, employee participation, knowledge sharing and procedural justice on employee performance; the study concludes that these constructs are key in enhancing the employee performance in the public health facilities in Turbo Sub- County. This is evidenced by the fact that these constructs jointly and independently affect to some magnitude employee performance as per the study findings. The effect of all the constructs of social correlates positively and significantly affects employee performance of the public health facilities. It therefore calls for the formulation, promotion of social correlates of work environment oriented policies and focusing on their implementation In consequence, it would become ingrained in management and operations of public health sector and not just an additional component of organizational policies thus high employee performance.

The current study provides absolute support to the suggestion that social correlates should be recognized as a significant precursor for the employee performance. The study implies that in the light of social correlates; supervisors support as a concept, when embraced by public health facilities, will contribute extensively to improving employee performance as compared to employee participation on improving employee performance in the public health sector. However, it should be adopted besides employee participation to enhance a synergistic relationship, which would eventually warrant high employee performance.

The study provides evidence that the factors associated with supervisors support are overly in dispensable in engendering high employee performance. Emotional support, instrumental support, appraisa support and information support bundled together significantly affect employee performance. In this regard as a strategic recipe which embeds these supervisors support dimension within the public health facility policy framework is evidently instrumental. Employee participation also remains a cornerstone for employee motivation and employee performance enhancement, this argument has espoused from the findings of this study that employee participation significantly affects performance. It therefore remains incumbent upon public health facilities' stake holders to synthesize employee participation oriented human resource policies in order to affect employee performance. In view of this, it remains inordinately necessary for public health facilities to analyze and strengthen their human resource practices which promote employee participation as this would motivate employees which are a source heightened employee performance. 
In the light of social correlates, supervisors support as a concept, when embraced by the public health facilities will contribute extensively to improving employee performance as compared to employee participation on employee performance. However this doesn't devalue role of employee participation, on employee performance but could highlight the priorities of public health facilities as far as ranking these variables. Such outcomes could also be ascribed to other factors not considered in this study which could have potentiated their effect on employee performance. However the social correlates should be bundled through mutually consistent policies to enhance their synergy in achieving high employee performance. In fine strategic orientation of these social correlates remains the cornerstone for enhancing employee performance.

\subsection{Implications and Contributions of the Study Findings}

The implications of this research findings is that the management of the public health facilities have been enlightened on the need of strengthening the implementation of social correlates in their facilities as a means of enhancing employee performance. In fine, the findings have contributed to human resource management in terms of providing valuable input to and awareness of the social correlates to consider with regard to enhancing employee performance. This has been illustrated empirically that the management should strive to synergize their social correlates in order to achieve maximal employee performance. In terms of policy the research findings have given eminence to embedding social correlates to organization policies in order to achieve high employee performance.

The theoretical implication of this study is that it supports and extends the Conservation of Resources theory and Social Exchange theory as it has casted more light on social correlates as a means through which an organization can enhance high employee performance. This findings supports the essence of bundling of social correlates through mutually consistent policies for purposes of galvanizing employee performance. The study has addressed the deficiencies in literature by extending studies on social correlates on employee performance in the Kenyan context as a developing country and specifically in the public health facilities. Besides, the study has addressed different outcomes of social correlates which is employee performance, other than employee satisfaction highlighted in a majority of studies. These findings remain vital for policy makers and practitioners in embracing social correlates in their policy formulations. However it problematizes the need to identify other social correlates that can be effectively be bundled to synergistically secure and sustain high employee performance.

\subsection{Recommendations}

In view of the findings of the study and the guidance from the literature review, it is apparent that strengthening the social correlates in the public health facilities is an important ingredient for eliciting high employee performance. While there are other factors crucial for employee performance. From the results, the public health facilities should pay more attention in addressing supervisors support, employee participation for purposes of increasing employee performance. In this regard, the current study makes the following recommendations:

Authorities of the public health facilities should acquire better employee performance by embracing supervisors support by giving impetus to emotional support, instrumental support, appraisal support and information support as precursors of employee motivation and performance. The organizations should improve on employee participation besides other social correlates constructs to achieve high employee performance in the public health facilities. However there is need for securing employee' participation through compliance teams in order to improve on quality service delivery and high level of satisfaction on the part of employees. Social correlates should be bundled through mutually consistent policies to enhance their synergy in achieving high employee performance. In fine strategic orientation of these social correlates remains the cornerstone for enhancing employee performance.

\subsection{Area for Further Research}

Several studies should be undertaken to gain a more comprehensive understanding on this theme in other contexts, future research should also include: Intervening effects of organization culture on the relationship between social correlates and employee performance in public health facilities and other industries.

\section{References}

[1]. Abdallah, M. T. (2015). The Impact of Practicing Procedural Justice on Employees Organizational Citizenship Behavior $(O C B)$ in the Jordanian Ministry of Justice. International Journal of Business and Social Science , 6, 8(1).

[2]. Allison, P. (2015). Heteroskedasticity. Retrieved 07 11, 2018, from https://www3.nd.edu/ rwilliam/

[3]. Arindam, N. (2016). 16 Factors that Lead to Poor Performance at the Workplace. Retrieved from http://blog.commlabindia.com/elearning-design/negativeperformance-factors assesed on 29/9/2017

[4]. Basaza, M. (2016). Factors affecting the performance of employees at the ministry of health headquarters in kampala, uganda. Unpublished thesis Uganda Technology and management university .

[5]. Benish, S., \& Raza, N. (2017). Impact of Workload and Job Complexity on Employee Job Performance with the Moderating Role of Social Support and Mediating Role of Job Stress: A Study of Travel agencies in Rawalpindi, Islamabad and AJK. Journal of Accounting \&Marketing, 6:214. doi:10.4172/2168-9601.1000214. 
[6]. Brannen, J., \& Gemma, M. (2012). Critical issues in designing mixed methods policy research. American Behavioural Scientist.

[7]. Bullen, P. (2016). How to choose a sample size (for the statistically challenged). Retrieved from http://www.tools4dev.org/resources/how-to-choose-asample-size/

[8]. Burgard, E. L. (2013). Ethical Concerns About Dual Relationships in Small and Rural Communities: A Review. Journal of European Psychology Students , 4, 69-77.

[9]. Chengedzai, M., \& Pooe, D. (2013). The relationship between employee satisfaction and organisational performance: Evidence from a South African government department. SA Journal of Industrial Psychology , 39(1).

[10]. Collis, J., \& Hussey, R. (2014). Business research: A practical guide for undergraduate and postgraduate students. Palgrave Macmillan.

[11].Cropanzano, R., \& Mitchell, M. (2005). Social Exchange Theory:An Interdisciplinary Review. Journal of Management , 31( 6), 874-900.

[12]. Crossman, A. (2017). Understanding Social Exchange Theory. Retrieved from https://www.thoughtco.com/social-exchange-theory3026634

[13]. DeVaus, D. (2002). Social Sciences Research Methodology. Allen \& Unwin.

[14]. Devender, S. M. (2014). HR Practices and Job Performance. IOSR Journal Of Humanities And Social Science (IOSR-JHSS), 19( 4 ) 55-61.

[15]. duPlooy, N., \& Viktor, H. (2002). Assessing and improving the quality of Knowledge Discovery Data. In Data warehousing and web engineering,. IRM Press, Hershey, PA: USA, pp 198-205.

[16]. Field, A. (2009). Discovering statistics using SPSS: and sex and drugs and rock ' $n$ ' roll (3rd edition). London: Sage.

[17]. Field, A. (2009). Discopering Statistics Using SPSS, Thrid Edition.

[18]. Francine, W. R. (2014). Enhancing Strategies to Improve Workplace Performance. Retrieved 6 1, 2018, from https://scholarworks.waldenu.edu/cgi/viewcontent.cgi?arti cle $=1105 \&$ context $=$ dissertations

[19]. Gerald, D., \& White, C. (2015). The Traits of Socially Innovative Companies. Retrieved from https://hbr.org/2015/04/the-traits-of-socially-innovativecompanies assesed on 27/9/17

[20]. Gupta, N., \& Kristensen, N. (2008). Work environment satisfaction and employee health panel : evidence from Denmark, France and Spain 1994-2001 . Eur J Health Econ , 9:51-61.

[21]. Kassachoon, K., \& Siminyu, M. (2014). Human Resources Strategy 2014-2018. Republic of kenya ministry of health .

[22]. Khan, S., \& Habib, U. (2011). Procedural justice and organizational performance. Abasyn Journal of Social Science, 4(7) 36.

[23]. Kothari, C. R., \& Garg, G. (2014). Research methodology Methods and Techniques. New Delhi: New Age International (P) Ltd.

[24]. Manyisa, Z., \& Elsie, J. (2017). Factors affecting working conditions in public hospitals: A literature review. International Journal of Africa Nursing Sciences, 6,28-38.
[25]. Marjolein, D., \& Harnmeijer, J. (2006). Improving health worker performance:in search of promising practices. Geneva, : WHO.

[26]. McDonald, J. H. (2017). Homoscedasticity and Heteroscedasticity. Retrieved 07 11, 2018, from https://stats.libretexts.org/Textbook_Maps/Biostatistics/B ook\%3A_Biological_Statistics_(McDonald)/4.0/4.05\%3A_H omoscedasticity_and_Heteroscedasticity

[27]. MoH. (2015). Ministry of Health Annual Health Sector Performance Report. (AHSPR) Government of Uganda . Kampala.

[28]. Ndegwa, J., \& Vincent, N. ( 2015). Knowledge Sharing, Organizational Learning and Performance of Top 100 Medium Enterprises in Kenya. 1st DBA-Africa Management Review International Conference (2015) 20th March , 2015 Pp. 42-65.

[29]. Osborne, J., \& Waters, E. (2002). Four assumptions of multiple regression that researchers should always test. Practical Assessment, Research \& Evaluation. 8(2).

[30]. Panaccio, A., \& Vandenberghe, C. ( 2011). The Relationships of Role Clarity and Organization-Based Self-Esteem to Commitment to Supervisors and Organizations and Turnover Intentions. Journal of applied social psychology, 41(6), 1455-1485

[31]. Pheko, M. (2013). The Impact of Resource Loss and Resource Gain among Botswana Employees: A Test of the Conservation of Resources Theory. International Journal of Business and Social Science , 4 (4).

[32]. Rucha, B. (2013). supervisor supportiveness global perspective. Retrieved from https://www.bc.edu/content/dam/files/research_sites/agi ngandwork/pdf/ assesed on 17 november 2017

[33]. Saajida, K., \& Ukpere, W. I. (2014). Employee Performance Management at a South African Government Organization. Mediterranean Journal of Social Sciences , 5(3).

[34].Selvarajan, T., \& Barjinder, S. (2016). Role of personality and affect on the social support and work. Journal of Vocational Behavior , 94 , 39-56.

[35].Sreevidya, U., \& Sunitha, K. (2011). Business research methods.

[36].Tabachnick, B. G., \& Fidell, L. S. (2001). Using Multivariate Statistics (4th ed.). Needham Heights, MA: Allyn and Bacon.

[37]. Usman, M. Z., \& Mahdi, A. (2012). The influence of organizational knowledge sharing on employee motivation. Retrieved 06 2018, 2018, from https://ieeexplore.ieee.org/document/6205011/

[38]. Wanjau, M. N., \& Kyongo, J. (2013). Contribution of Motivational Management to Employee Performance. International Journal of Humanities and Social Science, 3 (14).

[39]. Westerm, W., \& Simmons, B. (2007). The Effects of Work Environment on the Personality Performance Relationship: An Exploratory Study .Journal of Managerial Issues , XIX (2) 288-305.

[40]. Wheeler, A., \& Jonathon, R. H. (2009). A Conservation of Resources View of Person-Environment Fit. Retrieved from http://www.fitconference.com/2009/fri04 assesed on $31 / 10 / 2017$

[41]. Williams, R. (2015). Multicollinearity. Retrieved 07 26, 2018, from https://www3.nd.edu/ rwilliam/ 